\title{
The role of digital platforms in the transfer of knowledge and qualificationism: A study of digital sociology
}

\author{
Dwiki Faiz Sarvianto $^{1^{*}}$ \\ ${ }^{1}$ Rural Sociology, IPB University, Indonesia \\ *Corresponding author \\ E-mail address: faizdwiki@apps.ipb.ac.id \\ DOI: https://doi.org/10.21107/sml.v3i1.7125
}

\begin{tabular}{|c|c|}
\hline Article Info & Abstract \\
\hline $\begin{array}{l}\text { Keywords: } \\
\text { Digital sociology } \\
\text { Digital platform } \\
\text { Knowledge transfer } \\
\text { Qualificationism }\end{array}$ & $\begin{array}{l}\text { Indonesia has entered the digital era. Many sectors have been affected by } \\
\text { the development of existing digital devices and platforms, including the } \\
\text { higher education sector. Sociologically, this influence must be anticipated } \\
\text { because it will influence the transfer of knowledge and the phenomenon of } \\
\text { qualification. If the transfer of knowledge is ineffective, the quality of the } \\
\text { individual produced by the higher education level may be incompetent. This } \\
\text { study aimed to dissect the role and attention on the transfer of knowledge } \\
\text { that occurs, along with its impact during the digital era. This study used } \\
\text { a qualitative approach with descriptive methods through literature study } \\
\text { techniques to synthesize existing empirical facts. The primary empirical data } \\
\text { analyzed was the results of research on the transfer of specific knowledge and } \\
\text { the phenomenon of qualificationism. The researcher found that digitalization } \\
\text { influenced online learning and publication that were inter-related, despite } \\
\text { differences in access, skills and benefits for individuals. On the other hand, } \\
\text { the quality of higher education faced challenges because there was tacit } \\
\text { knowledge that must be fulfilled and the phenomenon of qualification as the } \\
\text { impact of higher education growth. }\end{array}$ \\
\hline
\end{tabular}

\section{Citation suggestion:}

Sarvianto, D. F. (2020). The role of digital platforms in the transfer of knowledge and qualificationism: A study of digital sociology. Simulacra, 3(1), 69-80. https://doi.org/10.21107/sml.v3i1.7125

Received 24 April 2020; Received in revised form 23 May 2020; Accepted 1 June 2020; Published online 25 June 2020. 


\section{Introduction}

Education is the most crucial domain in efforts to improve the quality and capacity of human resources. Education is undoubtedly expected to be able to increase knowledge and knowledge to alleviate the problems of every individual's life. Moreover, each of these individuals has their particular problems. Thus, the education of each individual must be fulfilled independently. However, in practice, of course, this problem in the education sector continues to exist in Indonesia. Indeed, this problem is not so easy to solve.

According to Afifah (2015), education problems in Indonesia are very complicated. Various problems have emerged, not only in terms of the concepts of education, regulations, and budget. However, the problem of implementing education in various systems in Indonesia also contributed to the complexity of the education problems in Indonesia. Not only that, but Afifah also acknowledged that achieving full participation is necessary for higher education was the main important point in improving the quality of human resources in Indonesia.

Although full participation in primary education almost includes every individual in Indonesia, data on participation in higher education still shows that participation is still minimal. Data from the Central Statistics Agency in 2020 showed that the School Participation Rate for higher education is still relatively low, at around 25.21 per cent. This fact is unfortunate because the role of higher education is essential for the future of the nation; Higher education plays a role as the producer of innovation to alleviate the problems of the nation (Sanderson, 1993).

Differences in access that affect social reality related to development can be one of the sociology studies in the higher education sector. Moreover, development influences social changes in society, ranging from poverty to other welfare indicators. Education is not only a matter of learning participation, but an understanding of the present conditions from the community, institutional, and educational institutions can be a sociological study as well (Maksum, 2013).

In connection with the current situation, the digitalization era is bringing digital devices and platforms into the spotlight. Digitalization in every sector, including higher education, also influences learning activities for everyone. It may already be familiar to ordinary people who have heard a lot about online learning or e-learning. However, there are certainly other issues that can be highlighted besides online activity, such as online publication and the knowledge of the individuals involved.

It is undeniable that, currently, there is a considerable amount of literature discussing the role of digital devices and platforms that tend to facilitate human activities, including in higher education (Lupton, 2015; Orton and Prior, 2013). This phenomenon is also considered a social change that shows a shift in the interaction between lecturers and students. Although the assumption is that digital devices and platforms exist to enable effective and efficient interaction in any activity, access to digitized education at any level must be questioned. Access to media/technology to connect individuals to online-based education channels is indeed not possessed by everyone. In line with the use, understanding and knowledge of each person will be different (Lupton, 2015). Of course, these two aspects will determine the difference in the acquisition of knowledge for each individual and the benefits gained by each individual from the use of technology (Lutz, 2019). Based on these facts, the assumptions that arise in this context indeed involve differences in each individual in the higher education sector, ranging from 
physical access, user skills, to the benefits received.

In the end, this condition will affect the capacity building in humans and how the objectives of the education process through digital devices and platforms are implemented. Karl Polanyi himself argued that the acquisition of knowledge as an individual's capacity has its characteristics. Thus, the form of information dissemination is also different, especially if factors such as digitalization are added into the equation (Iskandar and Subekan, 2018). The role of digital devices and their substance (platforms) to help the implementation of higher education become more effective and efficient, even without limits and can be accessed at any time.

However, at the level of social reality, there is an educational substance that should be achieved in line with the increasingly effective use of digital devices as the organizing medium. In this case, the spotlight falls into the quality of education received by individuals, especially in Indonesian higher education. Dore in Sanderson (1993) stated that in its development, the impact of education (especially at the level of higher education) would be directly felt by individuals themselves through educational qualifications. A similar situation also affects the quality of specific knowledge (tacit and explicit knowledge) as mentioned by Karl Polanyi. This opinion was reinforced by Sanderson (1993), who stated that knowledge related to the capacity and quality of individuals could be influenced by the media alongside modernity in a society which has entered the digital age.

Changes to the role of digital devices and platforms in education have their points to discuss concerning quality and knowledge and their relationship to the aim of increasing individual capacity through education, especially in higher education. Therefore, it could be assumed that the inclusion of digitalization had an impact on higher education in Indonesia. It could be further discussed through a current sociological perspective. These phenomena need to be explored because it will affect social change going forward, including its relationship with industrialization and qualificationism. Based on these facts, this study aimed to identify the role of digitalization in higher education and its obstacles. Then the study continued with an analysis of the relationship of the role of digital platforms to the quality of education.

\section{Method}

This study discussed the digitization of education from a sociological perspective. Specifically, this study addressed the role of education digitalization that affects the quality of education. The role of education digitalization was examined first through the digital sociology perspective by reviewing social interactions in the higher education sector. The role of digitalization is crucial to study because it is the starting point of change that is happening in the higher education sector today (Lupton, 2015). However, in reality, until now, there are obstacles in the role of digitalization that must be studied as well. Therefore, the digital divide and inequality could be related to their role. Then, the role was assumed to be related to the quality of education, in this context was individual knowledge and qualificationism.

Individual knowledge expressed by Karl Polanyi became one of the references in this study because this analysis was the most critical component in improving the quality of human resources in accordance with the objectives of education. The qualifications expressed by Dore were analyzed because they have become current social reality and even in the future about access to more open information in education (Sanderson, 1993). Thus, the quality of education in which 
there are two references was assumed to be influenced by the digitalization of education.

This study was conducted using a qualitative approach with descriptive methods according to the topics and titles raised. The data analysis technique was carried out through literature studies relating to the concepts of education digitalization, digital inequality, individual knowledge of Karl Polanyi's perspective, and qualificationism. The first step in this technique was the collection of literature based on statistical data, journals, and textbooks. Then, the study continued with an analysis of the role of digital, digital inequality, individual knowledge, and qualificationism in the present era and their interrelationships. Finally, the researcher synthesized new information about the development of the digital role of the device and its platform for these two phenomena (individual knowledge, according to Karl Polanyi and qualificationism).

\section{Results and Discussion}

The following discussion encompasses two subsections that are interrelated. The first part reviews the role of digitalization in the context of higher education in Indonesia and as well as its obstacles. The second part discusses the relationship of digitalization with the quality of current education. This connection is expected to indirectly review the impact of the problem on the process and the actors involved in higher education in Indonesia.

\section{The Role of Higher Education Digitalization: A Perspective of Digital Sociology}

Capacity building of individuals in the community is significant. Capacity building is usually connected with education, either formal or non-formal. Today, development is more advanced. Existing digitalization is sought to affect all sectors, including education (Mosco, 2017).

Along with the times and according to the mandate of the Law, if Indonesian education is to be developed, Communication Information Technology must be involved (Husaini, 2014).Although theimplementation of education at various levels has used a lot of digital media, it is precisely at the level of higher education that digital 'massiveness' is felt. Pranggono (2001) stated that the digitalization era requires universities everywhere, including Indonesia, to develop learning in accordance with science and innovation to, in turn, develop the nation. Therefore, the role of digitalization must be addressed positively by higher education as a solution to knowledge sharing to the current academic community.

The role of education digitalization can be entered into the realm of institutional management or directly in the implementation of individual learning of each individual (Husaini, 2014). Of course, the discussion from sociology perspectives must be related to the implementation of the students' learning process, which includes social interaction. This is the main point of the presence of the role of digital devices and platforms in the context of higher education. Interaction through digital devices and platforms allows the realization of online learning and publication processes (e-learning and online publications) between academics. However, it is also inevitable that digital devices and platforms also have other effects on other levels of education.

Implementation of online learning requires higher education to be able to run the necessary online process (e-learning). E-learning is a form of information device that is applied in education through a virtual system (Purbo, 2002). As according to Lupton (2015), the term e-learning carried out by 


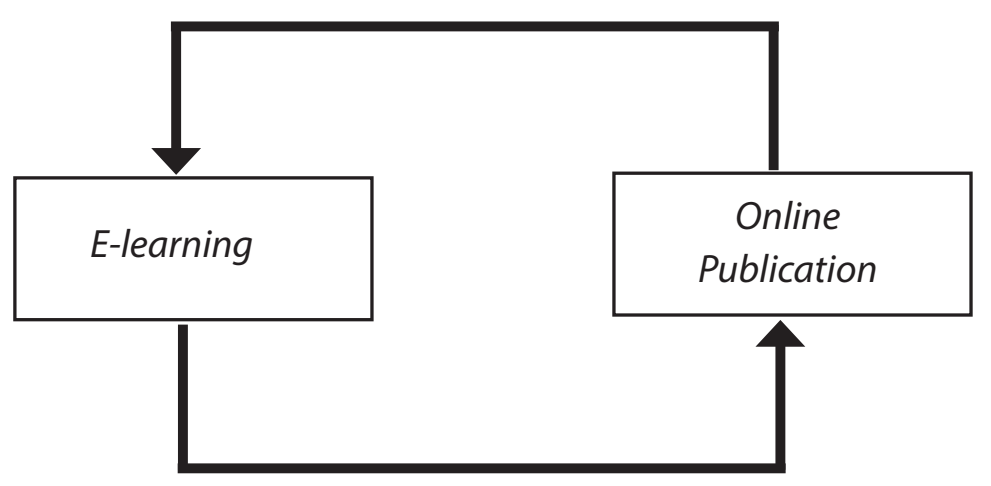

Figure 1. Relationship between the two roles of digitalization

(Reference: Lupton 2015; Orton and Prior, 2013)

academics of higher education is defined as online open lectures or Massive Open Online Courses (MOOCs). Even though the term is a little different, the application of e-learning can be done with the lecturer and student time simultaneously (synchronous) or not simultaneously (asynchronous). Not surprisingly, the presence of online learning in the context of education makes knowledge accessible at any time as long as the internet network is available.

Sociologically, it is not just a matter of time. Online learning also transforms the interaction model of lecturers and students to become indirect because it has gone through digital devices. This also applies to the class community and the relations of some students and lecturers outside the classroom. Educational subjects involved in this interaction carry out educational goals through the context of a borderless community due to the presence of digital devices (Orton and Prior, 2013). In Indonesia, the presence of digitalization in the higher education sector is often interpreted as online learning by several campuses, for example, IPB. In the online learning system, IPB uses a platform-based online system that can be accessed by their academics through their digital accounts and devices. Such access can be done anywhere and anytime provided that there is an adequate internet network. Therefore, the extensive interaction of space and time becomes a separate concept that arises in the student community to access knowledge due to the presence of the digital role now.

In addition to the matter of online learning processes carried out through digital devices directly to academics, the presence of online publications in the current era also helps the implementation of education more effectively and efficiently (Lupton, 2015). Online publications are in the form of a platform formed by research companies with the aim of not only being profitable but of course. It also plays a role in accommodating the results of previous and current research. It is undeniable that the role of digital platforms increasingly adds to the wealth of knowledge that can be used for information sources as well as for other academicians of higher education. Empirically, for lecturers, online publications can help them achieve their best academic reputation in the realm of higher education. Slightly different from lecturers, students are also assumed to be helped by the role of this online publication to explore research related to their final assignments and assignments. 
Thus, the acceleration of the process can also be experienced.

On the other hand, the existence of publications also influences the renewal of information so that the online learning process can happen very quickly. So, it can be imagined if there are no online publications. The information acquisition system in the online learning process will also be hampered in the higher education sector. In Indonesia, the undergraduate/graduate graduation system itself is also influenced by the online publication system. Students are expected to produce online publications in the form of international standard journals as a part of the learning process. Therefore, based on existing empirical data, in the role of digitalization itself, it can be said that in the process of learning and online publication (e-learning and online publication) there is a mutually meaningful relationship that can be seen in Figure 1 below.

It is undeniable that the role of digital devices and platforms is indeed making higher education easier in the future. However, in reality, this role has its obstacles and challenges. Every individual has access to different technologies, as well as the matter of digitizing higher education. Access is the first step that must be owned by an individual when one uses a digital device for any purpose. Access depends on differences in education, socio-economic status, geography, demography, and gender itself, while other matters that include other access differences can also be included in this indicator. These differences are referred to as the first level of the digital divide or firstlevel digital divide (Lutz, 2019; Van Deursen and Van Dijk, 2019).

In the context of higher education, these differences can be exemplified as follows. Students who are relatively younger at a relatively high economic level have relatively easy access to materials than other students who are a little older with a low economic level. From this example, it can be seen clearly that there are differences in access problems that occur, even though their status is the same as higher education students. However, according to Lutz (2019), in addition to material problems and resources (education, gender, geography, etc.), the digital benefits of each individual also need to be considered as the first stage in this gap. These benefits are reflected in the content available on digital devices and the ease of platform access.

The benefits can be seen by every individual with access to ownership of digital devices as the fulfillment of certain goals according to the context of desires that exist in individuals and the situation. The existing platform on digital devices is intended as the availability of all certain content to be able to continue to be present at all times; information can also be obtained quickly. In the context of higher education, academic content continues to be presented. Similar to the role of the previous digital platform, the content can be presented through online publications that can provide a function as a source of information to the academic community. The basis of this publication is in the form of a paid platform and even open access.

Finally, regarding the ease of accessing platforms in digital devices, according to Lutz (2019), it is intended as a specific facility that can have a separate impact on the skills possessed by each individual. Of course, in this context, if platform access is made with a high degree of difficulty, then the skills of each individual will also be presented with high proficiency as well. Simple platforms tend to be widely used by many individuals with very diverse characteristics, unlike the case with platforms that contain much content, such as social media. Of course, when it comes to higher education, this source of information can only be used by students. Meanwhile, for the lecturers, only 
a few access it. It can also be found as a connection between accessing devices and digital platforms to the skills possessed by individuals.

Before discussing skills, besides material access, according to Hadi (2018), in the first level of the digital divide, there is a motivation or choice that affects every individual in using a digital device. Then, when related to the context of higher education, students can choose a motivation to use digital devices or not or to use them properly or not. Therefore, access motivation can also encourage the use of digital devices and platforms for educational intensity. All of this depends on each student and material access. In fact, this will affect the real social implications of other spaces in the higher education sector itself.

Differences in access and functionality do not just carry out the use of the internet in the future. Differences in access and use of the internet will create learning spaces for media through existing digital devices and platforms. The learning space then creates the skills of each individual in using digital devices in any sector, including tertiary education.

Furthermore, differences in skills using digital devices and platforms enter into the second stage of the digital divide or secondlevel digital divide (Van Deursen and Van Dijk, 2019). The context of the second level of this gap can be exemplified as follows. Students are certainly more skilled than education staff or lecturers who rarely access digital or social media. The tendency of students to always use digital devices makes themselves more skilled or skilled. This development is seen in the situation that students can respond to content to create it as a fulfillment of academic assignments even to gain benefits in the form of material and other skills. Later, those things can then influence "digital" ethics also in the future or what can be called digital inequality or digital inequality (Lupton, 2015).

In brief from the previous explanation, the presence of digital inequality (digital inequality) is the development of the digital divide (digital divide), which often causes differences in skills also in playing digitally. Skills or skills in the use of digital devices themselves tend to include: operational sing, processing the information obtained, disseminating content to other individuals, to making content that should be relevant to the media. At the second level, it can be found that students who have access to technology with excellent skills will cause themselves to benefit from the presence of the role of digital platforms.

In the end, the difference in skills will affect the income of information or the benefits that result from participating in accessing information from digital (Buchi, 2017). Then, usefulness can also be an indicator of effective digital use for individuals or what can be called the third level of the digital divide or third-level digital divide. The presence of third-level digital divide is a continuation that should be analyzed thanks to the entry of digital technology into the community as internet users.

The impact of the use of the internet becomes a separate gap, also because of the effects presented by the internet. At this third level, Lutz (2019) states that each online activity of each individual will brings tangible benefits to its users. For example, someone can save money because of there is the internet, can find information cheaply and efficiently, so that it can increase other priorities in life. Likewise, what happens in the higher education sector, academicians must effectively be able to utilize internet services as a means of developing their capacity because of the wealth of information. Therefore, according to Lutz, this third level also makes the role of digital platforms 
also include the development of the status of individual users and the community. However, the benefits of this digitalization role will be biased later because of the dependence of digital platform users with the skills and access to the devices they have.

The challenges surrounding differences in access and skills must be responded positively and supported so that academics of higher education have their advantages regarding the digitization of devices and platforms. It is undeniable that in the issue of obstacles and challenges, access becomes a key factor for individuals who want a benefit from the digitalization of education. Access is also addressed by the private sector as information that can be beneficial. Technological resources, sophistication, and information in it, such as online publications, make the new economic system in terms of digitalization. This is equivalent to a statement from Kauppinen (2014) which revealed that because of the large amount of information present in the current era, knowledge had become a commodity in higher education that occurs in almost all countries, including Indonesia.

Even so, the transfer of knowledge that occurred did not necessarily effectively convey it entirely. There is a change in the quality of education in this context, because of the presence of digital itself. In addition, the quality of education to improve the quality of its human resources becomes its spotlight if knowledge transfer is less effective. Jobs that are present in the community will undoubtedly see the quality that exists in these individuals later, in this case, a matter of qualification. Therefore, it needs to be reviewed again about the role of existing digitalization of education to the quality of education, in this case, their knowledge and individual characteristics as educational targets to support the needs of employment.

\section{The Role of Digital Platforms on Education Quality}

The quality of education in Indonesia is undoubtedly the target of developing the quality of its human resources. The components contained in the quality of human resources are primarily a matter of knowledge of the individual. Knowledge is expected to be a thought process that can be used to overcome the problems of daily life wherever individuals are. Higher education is a place to hone knowledge of individuals who have the highest reputation than any other level. The role of digitalization is felt now, entering higher education also in Indonesia. The hope, of course, improving the quality of human resources in higher education will be able to meet effective employment opportunities to achieve the welfare of the nation. Therefore, the sharpening of knowledge in higher education can be influenced by the massive role of digitalization in the current era, as well as in printing the quality of human resources that will meet the needs of economic productivity.

Speaking about personal knowledge sharpening in the education process at the same time can be interpreted as the transfer of knowledge, Karl Polanyi has its views in the individual's knowledge. For him, there are two individual knowledge that can be used as a process of knowledge (education) towards others (Wahyuni, 2018). First, explicit knowledge or explicit knowledge, is one type of knowledge that is easily documented and formed, in this context knowledge can be provided in any form, both digital and conventional (Iskandar and Subekan, 2018). Second, implicit knowledge or tacit knowledge, which is the knowledge that is in the human mind, can be expressed through the implementation of the capabilities delivered in the direct form of its activities and by witnessing it or learning by doing and learning by watching. The 
form of tacit knowledge refers to personal knowledge possessed by individuals in the form of experiences, knowledge, insights, expertise, beliefs, to the personality of the individual that can be learned (Wahyuni, 2018).

In the context of education implementation through digitalization, the presence of digital devices and platforms positively affects the transfer of the two types of knowledge that have been alluded to. This in itself reflects that the process of transfer of knowledge on digital can only be applied to the explicit knowledge. Unlike the case with tacit knowledge, in this type, the difficulty will also be illustrated if the transfer process is not done directly.

According to Kauppinen (2014), tacit knowledge (i.e. know-how and knowwho) usually refers to skills, and it is not necessarily easy to communicate with other individual actors, or between organizations. The statement means that tacit knowledge usually refers to skills, and it is not always easy to communicate this kind of knowledge to other individuals. He further revealed that this was due to the source of knowledge that is in other people, has its specificities, such as communication skills, beliefs, ideology, and an in-depth perspective.

So, even with digital media in tertiary education, expertise and knowledge from lecturers, for example, it will be challenging to learn if it is tacit knowledge (for example self-management of lecturers, knowledge management, or personality). Therefore, the growth of the digital role itself in higher education does not guarantee the creation of the best quality human resources due to the difficulty in getting tacit knowledge available in the source of knowledge (e.g. lecturers). In fact, not guaranteed the superior human resources also influence the fulfillment of employment needs in the current era or affect the way of economic productivity in recruiting human resources.
Fulfilling superior human resource capacity in terms of economic productivity was introduced by Dore as a matter of qualification (Sanderson, 1993). According to him, qualificationism itself is a socioeconomic phenomenon that occurs today, where labor and expertise must be in accordance with the specific substance and objectives of existing industries. The presence of qualification is an industry demand in responding to the current digital era, but it does not look at the context of the digital role in education as well as the development of human resources in it.

The fact is that qualification is influenced indirectly from the process of transfer of knowledge previously discussed, the transfer is indeed challenging to fulfill in the current era, especially tacit knowledge. Not only starting from the matter of the process of knowledge transfer, but the development of qualificationism itself also influences the presence of the higher education industry in this context which can be called a corporate university. The presence of these institutions intends to meet the specific workforce as in the phenomenon of qualificationism occurring (Sanderson, 1993). In Indonesia, the development of corporate universities is relatively massive. Until recently, the presence of corporate-based educational institutions as donors has the primary segmentation for certain social classes in it. This is because the development of the times helped encourage that at the State University (PTN) itself there is no guarantee it will also create superior quality human resources in it.

Even so, it becomes a problem when higher education (including corporate universities) competes to fulfill existing private sector qualifications. Fulfillment of employment needs that are substantially needed by industry is not matched by the adequacy of higher education as well as corporate universities, but rather the 
occurrence of these institutional advantages along with their students as well. This problem is then, according to Sanderson (1993), referred to as an excess of graduates or over-education.

Over-education was placed by Sanderson as the first consequence of the presence of qualificationism in the current era. Complete if there is an increase in the number of people who hold an education certificate at a certain level, and if the number of jobs that require that level of education does not increase, then many diploma holders will not be able to obtain a job at that level. In the end, the jobs that are present will be obtained by holders of diplomas that are higher than needed, or for those who do not even have a higher education diploma; he will chase her. Therefore, over-education can also be said to be the cause and effect of the presence of existing qualification in the industry today (Sanderson, 1993).

After the number of diplomas a person has, the credibility of the diploma is also questionable. The process of education in higher education, in particular, becomes a separate problem as a second consequence with the presence of qualificationism. The implementation of education that does not pay attention to individual creativity, but because of pursuing a diploma is a significant problem in this context. Both corporate universities and other tertiary education, of course, it could be assumed only to hold an educational process to "catch up" to a diploma. The presence of higher education also pays attention to the learning process, curriculum, student activity, facilities, and so that human capacity development is genuinely achieved, and can even become an independent human being to produce himself.

Admittedly, the need for diplomas experienced by individuals and the organization of tertiary education in Indonesia does not all have bad characteristics. However, the need for a diploma accompanied by superior human capacity usually will be born from the process of providing competent education for individuals. Therefore, the phenomenon of the need for a proper diploma in the current

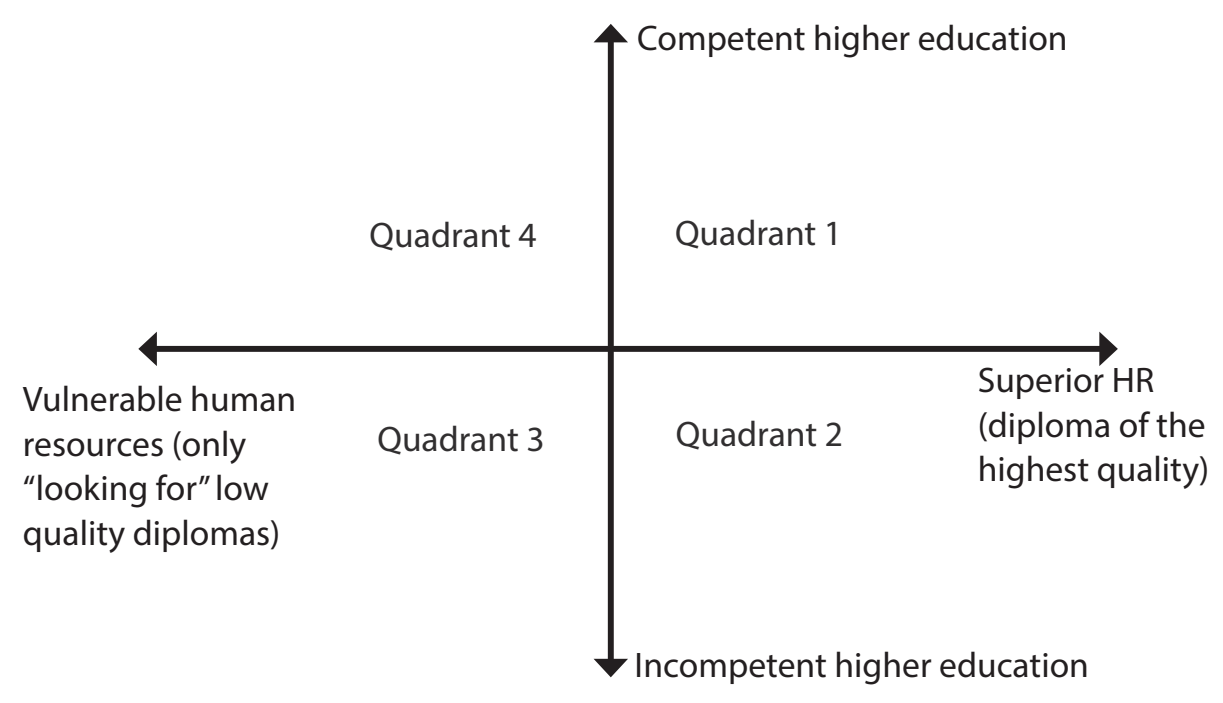

Figure 2.

Relationship between HR capacity and higher education implementation

(Reference: Sanderson 1993) 
era with the capacity in accordance with the capabilities of the educational process can be seen clearly in its position in Figure 2 below.

Figure 2 above shows that currently the level of human resource capacity with the capacity of providing education has a connection with one another in it. The position in these quadrants illustrates that Indonesia has a diversity of individuals in carrying out their education in the current era. Moreover, this is also encouraged by the phenomenon of qualificationism as an industrial target in creating human resources capable of operating its digital industry.

Quadrant 1 in Figure 2 was found that the quality of Human Resources (HR) that is superior is also directly proportional to the implementation of the educational process of the Higher Education(PT) as well. Quadrant 2 was found that the superior quality of human resources can also be born from universities that have not been competent. Quadrant 3 found that the educational process of a university that has not been competent can give birth to vulnerable human resources, in the sense that only formalities undergo higher education that is held. Quadrant 3 is undoubtedly a common problem that must be addressed in accordance with the development of the qualification phenomenon. As a result, if quadrant 3 is not adequately addressed, unemployment will increase dramatically everywhere. Finally, there is quadrant 4, from this it can be stated that competent universities will not only produce superior human resources as well, but there are also other motives from users (students) that they study only to obtain a diploma in the process.

Of the several quadrants that exist in the relationship of human resource capacity with the delivery of education, it can be said that the phenomenon of the development of digitalization can also affect the quality of human resources produced by higher education. However, the effect of digitalization is not necessarily directly to the quality of human resources and the implementation of education, in which there is a process of qualification in the industry that can be present through corporate universities according to the needs of the HR organization itself. Not to mention in the knowledge component, the issue of tacit knowledge that is difficult to transfer between individuals in the education process through digitalization is of particular concern. Therefore, the role of digitalization on the quality of education that occurs must be adequately addressed. The presence of an active lecturer-student role is undoubtedly the highest assumption to be realized so that the present higher education process can create superior Human Resources (HR) in accordance with the current economy and social reality. Similarly, the impact will reach the industry, and the industry can be fulfilled if the quality of human resources, especially in Indonesia is superior.

\section{Conclusion}

The development of digital technology is now also affecting several sectors, including higher education. Nowadays, the role of digital devices and platforms is also felt by users in the sector. The existence of online learning and publication systems has become a significant role that directly impacts the academic community. Even though it is efficient, all individuals do not necessarily feel the presence of the role of the digital platform because there are questions about accessing different devices, skills and benefits in it.

Likewise, the substance of the results of education consists of the transfer of knowledge and qualificationism. Even though the transfer of tacit knowledge is difficult, knowledge in this digital era must be managed so that the learning process carried out at any level of education can 
occur equally and effectively. Later this will then be able to bring a positive impact on the quality of individuals who are ready to enter industrialization in their work so that the qualification of higher education can be faced.

\section{Declaration of Ownership}

This article is our original work.

\section{Conflict of Interest}

There is no conflict of interest to declare in this article.

\section{Ethical Clearance}

This study was approved by the institution.

\section{References}

Afifah, N. (2015). Problematika pendidikan di Indonesia. Jurnal Elementary, 1(1), 4147.

Badan Pusat Statistik. (2020). Angka partisipasi sekolah (APS) menurut provinsi, 2011-2019. Badan Pusat Statistik.

Buchi, M. (2017). Digital inequalities: Differentiated internet use and social implications [Disertasi]. University of Zurich.

Hadi, A. (2018). Bridging Indonesia's digital divide: Rural-urban linkages. Jurnal Ilmu Sosial dan Ilmu Politik, 22(1), 17-33.

Husaini, M. (2014). Pemanfaatan teknologi informasi dalam bidang pendidikan (e-education). Jurnal Mikrotik, 2(1), 34-51.

Iskandar, A., \& Subekan, A. (2018). Pengaruh personal knowledge, job procedure, dan technology terhadap kinerja pegawai organisasi publik. Jurnal Riset Manajemen Sains Indonesia, 9(2), 168-192. https://doi. org/10.21009/JRMSI.009.2.01
Kauppinen, I. (2014). Different meanings of knowledge as commodity in the context of higher education. Journal of Critical Sociology, 40(3), 393-409. https://doi. org/10.1177/0896920512471218

Krantz, L. (2001). The sustainable livelihood approach to poverty reduction. Swedish International Development Cooperation Agency.

Lupton, D. (2015). Digital sociology. Routledge.

Lutz, C. (2019). Digital inequalities in the age of artificial intelligence and big data. Journal of Hum Behav \& Emerg Tech, 4(1), 141-148. https://doi.org/10.1002/hbe2.140

Maksum, A. (2013). Sosiologi pendidikan. Fakultas Tarbiyah dan Keguruan UIN Sunan Ampel Surabaya.

Mosco, V. (2017). Society now: Becoming digital. Emerald Publishing.

Orton, K., \& Prior, N. (2013). Digital sociology: Critical perspectives. The Palgrave Macmillan.

Pranggono, B. (2001). Pendidikan tinggi di era digital dan tantangan bagi Unisba. Jurnal Mimbar, 17(1), 1-19.

Purbo, O. (2002). Teknologi e-learning. Elex Media Komputindo.

Sanderson, S. (1993). Sosiologi makro: Sebuah pendekatan terhadap realitas sosial. Rajawali Pers.

Van Deursen, AJAM., \& Van Dijk, JAGM. (2019). The first-level digital divide shifts from inequalities in physical access to inequalities in material access. Journal of NewMediaESociety, 21(2),354-375.https:// doi.org/10.1177/1461444818797082

Wahyuni, A. (2018). Pengaruh tacit dan explicit knowledge untuk meningkatkan kinerja IKM. Jurnal Ilmiah Teknologi Informasi Terapan, 5(1), 45-50. https://doi. org/10.33197/jitter.vol5.iss1.2018.252 